Wright State University

CORE Scholar

Physics Faculty Publications

Physics

$2-1-2002$

\title{
Production of Nitrogen Acceptors in ZnO by Thermal Annealing
}

N. Y. Garces

N. C. Giles

L. E. Halliburton

G. Cantwell

D. B. Eason

See next page for additional authors

Follow this and additional works at: https://corescholar.libraries.wright.edu/physics

Part of the Physics Commons

\section{Repository Citation}

Garces, N. Y., Giles, N. C., Halliburton, L. E., Cantwell, G., Eason, D. B., Reynolds, D. C., \& Look, D. C. (2002).

Production of Nitrogen Acceptors in ZnO by Thermal Annealing. Applied Physics Letters, 80 (8),

1334-1336.

https://corescholar.libraries.wright.edu/physics/77

This Article is brought to you for free and open access by the Physics at CORE Scholar. It has been accepted for inclusion in Physics Faculty Publications by an authorized administrator of CORE Scholar. For more information, please contact library-corescholar@wright.edu. 


\section{Authors}

N. Y. Garces, N. C. Giles, L. E. Halliburton, G. Cantwell, D. B. Eason, D. C. Reynolds, and David C. Look 


\title{
Production of nitrogen acceptors in $\mathrm{ZnO}$ by thermal annealing
}

\author{
N. Y. Garces, N. C. Giles, and L. E. Halliburton ${ }^{\text {a) }}$ \\ Department of Physics, West Virginia University, Morgantown, West Virginia 26506 \\ G. Cantwell and D. B. Eason \\ Eagle-Picher Technologies, LLC, Miami, Oklahoma 74354 \\ D. C. Reynolds and D. C. Look \\ Semiconductor Research Center, Wright State University, Dayton, Ohio 45435
}

(Received 19 October 2001; accepted for publication 11 December 2001)

\begin{abstract}
Nitrogen acceptors are formed when undoped single crystals of zinc oxide $(\mathrm{ZnO})$ grown by the chemical-vapor transport method are annealed in air or nitrogen atmosphere at temperatures between 600 and $900{ }^{\circ} \mathrm{C}$. After an anneal, an induced near-edge absorption band causes the crystals to appear yellow. Also, the concentration of neutral shallow donors, as monitored by electron paramagnetic resonance (EPR), is significantly reduced. A photoinduced EPR signal due to neutral nitrogen acceptors is observed when the annealed crystals are exposed to laser light (e.g., 364, 442, 458 , or $514 \mathrm{~nm}$ ) at low temperature. The nitrogens are initially in the nonparamagnetic singly ionized state $\left(\mathrm{N}^{-}\right)$in an annealed crystal, because of the large number of shallow donors, and the light converts a portion of them to the paramagnetic neutral acceptor state $\left(\mathrm{N}^{0}\right)$. (C) 2002 American Institute of Physics. [DOI: 10.1063/1.1450041]
\end{abstract}

At the present time, zinc oxide is receiving considerable attention because of its potential application as an ultraviolet light emitter. ${ }^{1-3}$ One of the major obstacles in the development of this material, however, is the difficulty encountered in finding an efficient $p$-type dopant. Most of today's $\mathrm{ZnO}$ crystals contain significant concentrations of shallow donors and, thus, are $n$ type. Known acceptors in $\mathrm{ZnO}$ include lithium, ${ }^{4,5}$ copper, ${ }^{6,7}$ and zinc vacancies, ${ }^{8,9}$ but all of these are deep acceptors and do not contribute significantly to hole conduction. Recently, thin-film growers have focused on nitrogen as a shallower acceptor in $\mathrm{ZnO} .{ }^{10-13}$ They have demonstrated that nitrogen will enter the films if $\mathrm{N}_{2} \mathrm{O}$ or $\mathrm{NH}_{3}$, depending on the growth technique, is used as a source. With these successes, it is important to better understand the properties and behavior of nitrogen in $\mathrm{ZnO}$.

In the present letter, we describe the production of nitrogen acceptors in undoped single crystals of $\mathrm{ZnO}$ by annealing in air, or nitrogen, to temperatures between 600 and $900{ }^{\circ} \mathrm{C}$. These treatments cause the following effects: (1) an optical absorption band appears in the near-edge region, extending out to $550 \mathrm{~nm}$; (2) the concentration of neutral shallow donors is greatly decreased; and (3) the electron paramagnetic resonance (EPR) signal of the neutral nitrogen acceptor can be photoinduced. This nitrogen EPR signal has been recently reported by Carlos, Glaser, and Look ${ }^{14}$ and is unambiguously assigned to the neutral nitrogen acceptor because of its uniquely characteristic three-line hyperfine pattern, arising from a nearly $100 \%$ abundant $I=1$ nucleus (in this case, the ${ }^{14} \mathrm{~N}$ isotope). We have found that this neutral nitrogen EPR signal can be photoinduced at low temperature with a variety of laser wavelengths (e.g., 364, 442, 458, and $514 \mathrm{~nm}$ ). Our results suggest that, following a thermal anneal, the nitrogen acceptors compensate a portion of the donors (i.e., the nitrogens are in the nonparamagnetic singly

${ }^{a)}$ Electronic mail: lhallibu@wvu.edu ionized charge state $\left(\mathrm{N}^{-}\right)$and the concentration of neutral shallow donors has decreased). If an annealed sample is exposed to light at low temperature, some of these singly ionized nitrogen acceptors are converted to the paramagnetic neutral acceptor charge state $\left(\mathrm{N}^{0}\right)$.

The $\mathrm{ZnO}$ crystals used in the present study were grown at Eagle-Picher (Miami, OK) using the chemical-vapor transport method. Although material from six separate growth runs was investigated (with similar results from all six), most of the data reported here were taken from one sample cut from a 1-mm-thick $c$ plate. The dimensions of this sample were $8 \times 2.5 \times 1 \mathrm{~mm}^{3}$. During a thermal anneal, the sample was placed in a quartz tube extending through a small horizontal furnace. The ends of the tube were either left open to the air, giving a semistatic atmosphere, or one end was connected to a source of flowing nitrogen or helium gas. At the start of a thermal anneal, the furnace was stabilized at the desired temperature, and then the sample was inserted. At the end of an anneal, the sample was removed from the hot furnace and cooled to room temperature in less than $1 \mathrm{~min}$.

The EPR data were obtained using a Bruker EMX spectrometer operating near $9.477 \mathrm{GHz}$. An Oxford Instruments model ESR-900 helium-gas flow system provided temperature control. The excitation sources for the photoinduced EPR were a cw argon-ion laser (364, 458, and $514 \mathrm{~nm})$ and a cw helium-cadmium laser (442 $\mathrm{nm}$ ). Optical data were taken on a Cary 14 spectrophotometer.

As shown in Fig. 1(a), an EPR signal due to neutral shallow donors was present in our as-grown, unannealed $\mathrm{ZnO}$ samples. The data in Fig. 1 were taken near $6.5 \mathrm{~K}$ with the magnetic field perpendicular to the $c$ axis of the crystal. This large EPR signal, with $g_{\|}=1.957$ and $g_{\perp}=1.956$, has been widely reported in the $\mathrm{ZnO}$ literature. Its position is independent of the shallow donor identity (i.e., earlier investigators have shown that $\mathrm{Al}, \mathrm{Ga}$, and In give identical signals). ${ }^{15-18}$ At the shallow-donor concentrations present in 


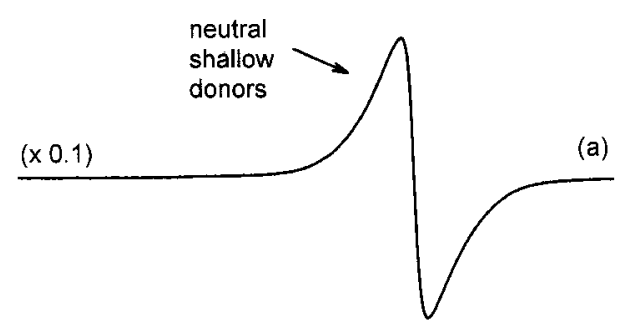

(b)
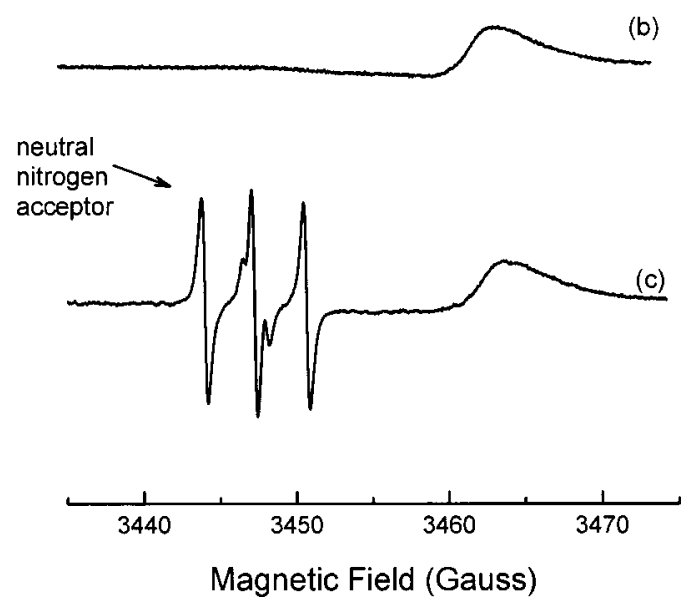

FIG. 1. EPR spectra taken at $6.5 \mathrm{~K}$ from a $\mathrm{ZnO}$ crystal (a) before a thermal anneal; (b) in the dark after a thermal anneal at $700^{\circ} \mathrm{C}$ in air for $30 \mathrm{~min}$; and (c) with $458 \mathrm{~nm}$ illumination after the $700{ }^{\circ} \mathrm{C}$ anneal. The magnetic field was perpendicular to the $c$ axis. Note that trace (a) is actually ten times larger than shown. The signal at higher field is due to neutral shallow donors and the photoinduced signal at lower field is due to neutral nitrogen acceptors.

our as-grown samples, there is no resolved hyperfine pattern associated with this signal. It is important to note that this EPR signal at " $g=1.96$ " is not due to singly ionized oxygen vacancies. A different EPR signal, with $g_{\|}=1.9945$ and $g_{\perp}$ $=1.9960$, is normally seen only after particle irradiation and has been unambiguously assigned to the paramagnetic state of the oxygen vacancy. ${ }^{19}$

In Fig. 1(b), we show the EPR spectrum taken after the $\mathrm{ZnO}$ crystal was annealed at $700{ }^{\circ} \mathrm{C}$ in air for $30 \mathrm{~min}$. Prior to this $700^{\circ} \mathrm{C}$ anneal, the crystal had been annealed for 30 min each at a series of lower temperatures, starting at $300{ }^{\circ} \mathrm{C}$ and increasing by $50{ }^{\circ} \mathrm{C}$ increments until $700^{\circ} \mathrm{C}$ was reached. There is a significant reduction in the size of the neutral shallow donor EPR signal and its shape also has changed dramatically. Comparing the spectra in Figs. 1(a) and 1(b) shows that the annealing treatments decreased the donor EPR signal by a factor of 50. The spectrum in the annealed sample appears to have its "phase" inverted, and this suggests that there is microwave power saturation of the signal (i.e., a longer spin relaxation time arises when the interaction between adjacent neutral donors is reduced because of larger separation distances). The decrease in the concentration of neutral shallow donors, caused by the thermal anneal and observed in the EPR experiments, has been verified by recent Hall-effect measurements on similar $\mathrm{ZnO}$ samples, and the results will be reported in a later paper. In that study, we found that annealing a $\mathrm{ZnO}$ crystal in air at $750^{\circ} \mathrm{C}$ for $30 \mathrm{~min}$ decreased the room-temperature electron concentration from $1.0 \times 10^{17}$ to $5.1 \times 10^{16} \mathrm{~cm}^{-3}$.
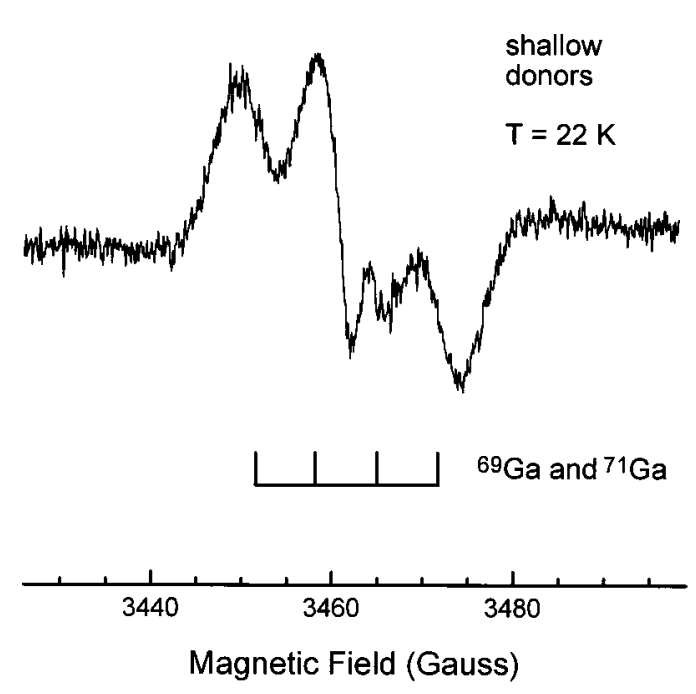

FIG. 2. EPR spectrum of the neutral shallow donors in a $\mathrm{ZnO}$ crystal annealed in air at $700{ }^{\circ} \mathrm{C}$. The temperature was $22 \mathrm{~K}$ and the magnetic field was perpendicular to the $c$ axis.

A closer examination, at higher temperature, of the shallow donor EPR signal in Fig. 1(b) shows that there are two contributing centers, and that one of the centers has a partially resolved hyperfine pattern. Figure 2 shows these donor signals, taken at $22 \mathrm{~K}$ with the magnetic field perpendicular to the $c$ axis. As the temperature is raised from 6 to $22 \mathrm{~K}$, the donor signal evolves from a distorted, highly saturated shape to a normal unsaturated derivative shape [i.e., compare the spectrum in Fig. 1(b) to the spectrum in Fig. 2]. Although the structure in Fig. 2 is not well resolved, we suggest that a four-line pattern is present, indicated by the stick diagram, and that a single larger line is present just to the low-field side of the center of the four lines. We attribute the four-line donor signal in Fig. 2 to neutral shallow gallium donors, with the four lines arising from the hyperfine interactions with the two isotopes. The hyperfine splitting for the gallium spectrum in Fig. 2 is $6.7 \mathrm{G}$, and this compares favorably to the estimate of $4.2 \mathrm{G}$ made by Gonzalez et al. ${ }^{18}$ from an unresolved EPR spectrum in a gallium-doped sample. It is possible that chlorine donors might be responsible for the fourline pattern in Fig. 2, but we consider this to be less likely because of the agreement with the earlier Ga study. We did not observe, in our samples, the ten-line EPR spectrum previously assigned to indium shallow donors. ${ }^{18}$

In Fig. 1(c), we show the effect of laser light on our crystal that was annealed in air at $700{ }^{\circ} \mathrm{C}$. The sample was held in the microwave cavity at $6.5 \mathrm{~K}$ with the magnetic field perpendicular to the $c$ axis, and the laser beam entered the cavity through slots. Before exposing the sample to the laser, no acceptor signals are observed [see Fig. 1(b)]. With the light on, we see a large three-line EPR spectrum appear [see Fig. (1c)]. This spectrum has been assigned to the neutral nitrogen acceptor by Carlos, Glaser, and Look. ${ }^{14}$ Its threeline hyperfine pattern arises from an interaction with one ${ }^{14} \mathrm{~N}$ nucleus. These three primary lines shift, but do not split, when the magnetic field is rotated relative to the crystal axes. From the angular dependence, the acceptor is shown to have axial symmetry about the $c$ axis $\left(g_{\|}=1.9948, g_{\perp}=1.9632\right.$, $A_{\|}=81.3 \mathrm{MHz}$, and $A_{\perp}=9.5 \mathrm{MHz}$ ). When the magnetic field is nearly perpendicular to the $c$ axis, "forbidden" transitions 


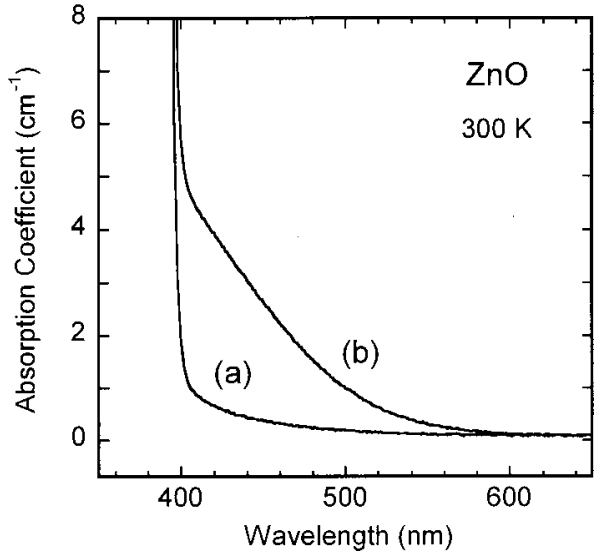

FIG. 3. Optical absorption spectrum of a $\mathrm{ZnO}$ crystal annealed in air at $700{ }^{\circ} \mathrm{C}$. The data were taken at room temperature. Trace (a) was taken before the anneal and trace (b) was taken after the anneal.

acquire significant intensity and the EPR spectrum appears more complicated than a simple three-line pattern. Also, hyperfine lines from the four neighboring ${ }^{67} \mathrm{Zn}$ nuclei are observed, with splittings of $13.2 \mathrm{G}$ for the axial neighbor and $6.5 \mathrm{G}$ for the three basal plane neighbors when the field is parallel to the $c$ axis. The neutral nitrogen EPR spectrum is best observed between 5 and $10 \mathrm{~K}$. After being produced with light at $6.5 \mathrm{~K}$, the EPR signal decays in the dark at this same temperature over a period of several hours.

The photoinduced neutral nitrogen acceptor signal in Fig. 1(c) can be formed with wavelengths below the band gap. We found that lasers operating at 364, 442, 458, and 514 $\mathrm{nm}$ are all effective in producing the nitrogen EPR signal, while excitation at $633 \mathrm{~nm}$ did not produce the signal. These observations are consistent with a yellow coloration that forms in the crystals when annealed above $600{ }^{\circ} \mathrm{C}$ in air or nitrogen. We show this absorption in Fig. 3 for the crystal heated to $700{ }^{\circ} \mathrm{C}$ for $30 \mathrm{~min}$ (this is the same sample used in Figs. 1 and 2). These data were taken with unpolarized light propagating along the $c$ axis. A near-edge absorption is present in the annealed sample. At $10 \mathrm{~K}$, the optical absorption band narrows slightly and the fundamental absorption edge moves to higher energy, but the peak is still not resolved. The laser wavelengths that are effective in producing the nitrogen EPR signal all fall within the new band. We suggest that this near-edge absorption may represent transitions from singly ionized nitrogen acceptors to shallow donors and the conduction band or from singly ionized nitrogen acceptors to "deep" levels, such as transition-metal impurities or intrinsic defects.

The following observations relate to the process by which nitrogen acceptors are formed in $\mathrm{ZnO}$. We found that measurable concentrations of the neutral nitrogen acceptor EPR signal could not be photoinduced in $\mathrm{ZnO}$ crystals annealed in air at temperatures below $600{ }^{\circ} \mathrm{C}$ or above $900^{\circ} \mathrm{C}$. Also, there was only a small reduction (a factor of 2 ) in the neutral donor concentration and no photoinduced nitrogen EPR signal in a sample annealed at $750^{\circ} \mathrm{C}$ in flowing helium gas, even though similar anneals in air and nitrogen produced large effects. A final result refers to the distribution of photoactive nitrogen acceptors in a crystal annealed in air at $700^{\circ} \mathrm{C}$ for $1 \mathrm{~h}$ (the sample was a $c$ plate initially $1.0 \mathrm{~mm}$ thick). A "thinning" experiment was performed, where the neutral nitrogen EPR signal was repeatedly measured as material was removed from the two sides by grinding (i.e., after each removal step, the sample was cooled to $6.5 \mathrm{~K}$ and illuminated with $442 \mathrm{~nm}$ light to induce the EPR signal). We found that the photoinduced nitrogen acceptors were not distributed uniformly, even though they appeared through most of the crystal. Specifically, the number of photoinduced acceptors dropped to $58 \%$ of the 1 -mm-thick value when the crystal was thinned to $0.95 \mathrm{~mm}$, they dropped to $23 \%$ of the $1 \mathrm{~mm}$ value when the thickness was $0.80 \mathrm{~mm}$, and they dropped to $12 \%$ of the $1 \mathrm{~mm}$ value when the thickness was $0.50 \mathrm{~mm}$. These results suggest that our production of nitrogen acceptors in $\mathrm{ZnO}$ does not occur simply as a result of the thermal activation of nitrogen that may have been uniformly incorporated in the crystal during growth. It is also clear that the production of nitrogen acceptors is not restricted to a small region near the surface of the crystal.

In summary, we have described the production of nitrogen acceptors in $\mathrm{ZnO}$ by annealing in air or nitrogen at temperatures in the $600-900{ }^{\circ} \mathrm{C}$ range. The active nitrogen acceptors introduced during these treatments provide compensation for the shallow impurity donors. We have shown that, after an anneal, the EPR signal of the neutral nitrogen acceptor can be photoinduced with below-band-gap light. This is consistent with the induced optical absorption that accompanies the formation of nitrogen acceptors and extends from the band edge to $550 \mathrm{~nm}$. We did not find EPR signals associated with zinc vacancies, zinc interstitials, or oxygen vacancies in our as-grown or annealed crystals.

This work was supported at West Virginia University by the Air Force Office of Scientific Research (Grant No. F49620-00-1-0301).

${ }^{1}$ D. C. Reynolds, D. C. Look, and B. Jogai, Solid State Commun. 99, 873 (1996).

${ }^{2}$ D. M. Bagnall, Y. F. Chen, Z. Zhu, T. Yao, S. Koyama, M. Y. Shen, and T. Goto, Appl. Phys. Lett. 70, 2230 (1997).

${ }^{3}$ Z. K. Tang, G. K. L. Wong, P. Yu, M. Kawasaki, A. Ohtomo, H. Koinuma, and Y. Segawa, Appl. Phys. Lett. 72, 3270 (1998).

${ }^{4}$ O. F. Schirmer, J. Phys. Chem. Solids 29, 1407 (1968).

${ }^{5}$ O. F. Schirmer and D. Zwingel, Solid State Commun. 8, 1559 (1970).

${ }^{6}$ R. E. Dietz, H. Kamimura, M. D. Sturge, and A. Yariv, Phys. Rev. 132, 1559 (1963).

${ }^{7}$ R. Dingle, Phys. Rev. Lett. 23, 579 (1969).

${ }^{8}$ A. L. Taylor, G. Filipovich, and G. K. Lindeberg, Solid State Commun. 8, 1359 (1970)

${ }^{9}$ D. Galland and A. Herve, Phys. Lett. 33A, 1 (1970).

${ }^{10}$ K. Iwata, P. Fons, A. Yamada, K. Matsubara, and S. Niki, J. Cryst. Growth 209, 526 (2000).

${ }^{11}$ Y. Liu, C. R. Gorla, S. Liang, N. Emanetoglu, Y. Lu, H. Shen, and M. Wraback, J. Electron. Mater. 29, 69 (2000).

${ }^{12}$ W. Xinqiang, Y. Shuren, W. Jinzhong, L. Mingtao, J. Xiuying, D. Guotong, L. Xiang, and R. P. H. Chang, J. Cryst. Growth 226, 123 (2001).

${ }^{13}$ M. Joseph, H. Tabata, H. Saeki, K. Ueda, and T. Kawai, Physica B 302303, 140 (2001).

${ }^{14}$ W. E. Carlos, E. R. Glaser, and D. C. Look, Physica B 308-310, 976 (2001).

${ }^{15}$ R. J. Kokes, J. Phys. Chem. 66, 99 (1962).

${ }^{16}$ M. Schulz, Phys. Status Solidi A 27, K5 (1975).

${ }^{17}$ D. Block, A. Herve, and R. T. Cox, Phys. Rev. B 25, 6049 (1982).

${ }^{18}$ C. Gonzalez, D. Block, R. T. Cox, and A. Herve, J. Cryst. Growth 59, 357 (1982).

${ }^{19}$ J. M. Smith and W. E. Vehse, Phys. Lett. 31A, 147 (1970). 